To cite:

Wolfe, Joseph D., Bauldry, Shawn, Hardy, Melissa A., and Pavalko, Eliza K. (2018). Multigenerational Attainments, Racial Inequalities, and the Mortality of Silent Generation Women. Journal of Health and Social Behavior 59(3): 335-351.

\title{
Multigenerational Attainments, Race, and Mortality Risk Among Silent Generation Women
}

\author{
Joseph D. Wolfe ${ }^{1}$, Shawn Bauldry ${ }^{2}$, Melissa A. Hardy ${ }^{3}$, and Eliza K. Pavalko ${ }^{4}$ \\ ${ }^{1}$ University of Alabama at Birmingham \\ ${ }^{2}$ Purdue University \\ ${ }^{3}$ Pennsylvania State University \\ ${ }^{4}$ Indiana University
}

\begin{abstract}
This study extends health disparities research by examining racial differences in the relationships between multigenerational attainments and mortality risk among "SilentGeneration" women. Anemerging literature suggests that the socioeconomic attainments of adjacent generations, one's parents and adult children, provide an array of lifeextending resourcesin old age. Priorresearch, however, has demonstratedneitherhowmultigenerational resourcesare implicated in women's longevity nor how racial disparities faced by Silent Generation women may differentially structure the relationships between socioeconomic attainments and mortality. With data from the National Longitudinal Survey of MatureWomen, the analysis provided evidence of a three-generation model in which parent occupation, family wealth, and adultchild education were independently associated with women's mortality. Although we found evidence of racial differences in the associations between parental, personal, and spousal education and mortalityrisk, the education of adultchildren was arobust predictor of survival forblackand whitewomen.
\end{abstract}

\section{Keywords}

gender, health disparities, mortality, race, socioeconomic status

Education is a well-established correlate of longevity across genders and races (Hummer and Laniscy 2011), but its association with white women's mortality grew substantially larger during the latter twentieth and early twenty-first centuries (see Montez and Zajacova 2014). This finding has gamered the attention of social scientists, and recentstudieshaveidentifiedanumber of social and behavioral mechanisms that help explain the widening educationgapin whitewomen'smortality $(\mathrm{Ho}$ and Fenelon 2015; Montez and Zajacova 2013). Although this line of research has provided important insights into our understanding of health disparities among women, it has yet to examine whether the sunvival of older cohorts of white and black women is related to the attainments of multiple familial generations.

The majority of research on U.S. mortality disparities focuses on individual characteristics, but an emerging literaturesuggeststhatsunvival isalsolinked to adjacent generations —one's parents and adult children (Friedman and Mare 2014; Pudrovska 2014; Torssander 2013). Although this literature offers evidence of a 
multigenerational structure in mortality among older adults, ithas neitherempincally tested thisstructurein its entirety nor considered the implications of race in the transfer of health advantages across multiple generational lines. Thus, inthisstudy we ask:

1) Are parent, personal, and adult child attainments independently related to women's chances of survival in later adulthood?

2) Does race differentially shape any observed relationship between multigenerational attainments and women's mortalityrisk?

Toaddress these questions, weexamine data from the National Longitudinal Survey of Mature Women (NLS-MW), a nationally representative sample of women aged 30 to 44 in 1967 . This birth cohort of women were followed for over three decades and provided information on the socioeconomic attainments of multiple generations within their families. Distinguishing between birth cohort (or simply cohort) and familial generation (or simply generation) is key to understanding both our conceptual framework and our analytical approach. In line with life course scholarship, we define cohort as those who are born in broadly similar historical periods, whereas generation refers to one's position in the line of descent within a family (Alwin and McCammon 2003; Elder and George 2016). Each generation is by definition in a different cohort, meaning that every generation is exposed to unique historical contexts and attainment structures. Thus, we begin by developing a conceptual model of multigenerational attainments and mortality, and to operationalize this model, we then review several historical events and cultural and demographic trends throughout the twentieth century that structured attainment opportunities among Silent Generation women, theirparents, and their adultchildren.

\section{BACKGROUND}

\section{MultigenerationalModelsof Attainment and Health}

Recent scholarship in stratification and demography argues for a non-Markovian process of inheritance in which the socioeconomic attainments of one generation directly influence the life chances of two or more subsequent generations (Mare 2011; Mare 2014). In contrast, earlier work generally supported a Markovian pattern in which grandparents' (G1) socioeconomic attainment only indirectly influenced grandchildren's (G3) attainment through parents' (G2) characteristics (Warren and Hauser 1997). A nonMarkovian pattern, however, suggests that a mix of formal and informal social institutions directly link the attainment of $G_{1}$ to the life chances of both $G_{2}$ and $G_{3}$ (Mare 2011). A similar model is being considered in studies on health disparities (Huang et al. 2015; LêScherban et al. 2014), and like scholarship on status attainment, this research emphasizes the benefits of $\mathrm{G}_{1}$ attainments for the health of subsequent generations. Forlateradulthoodand old age, however, an integration of recent studies on parent and adult child attainments and mortality risk in older populations suggests an alternative multigenerational structure mightexist.

\section{Adjacent Generations and Mortality in Later Adulthood}

Anemerging body of researchsuggeststhatmortalityin later adulthood and old age is related not only to personal attainments $\left(\mathrm{G}_{2}\right)$ butalsotothe attainments of one's parents ( $\left.G_{1}\right)$ and adult children $\left(G_{3}\right)$, what we refer to as adjacent generations (Wolfe et al. 2018). Specifically, research within the "long arm" and "social foreground" perspectives. Research on the long arm of childhood conditions argues that parent attainments are linked to mortality in later life by way of a complex 
mixture of biological and social mechanisms (Hayward and Gorman 2004; Pudrovska 2014). From a biological standpoint, socioeconomic deprivation early in life may permanentlydamagephysiologicalfunctioning, leading toagreaterriskofdeveloping chronic diseaseslaterin life (see Almond and Curie 2011). Furthermore, an early deficit of socioeconomic resources can also be the catalyst for a lifetime of socioeconomic difficulties and social adversities that incrementally increase the risk of mortality over time through an accumulation of environmental exposures and stress (Pudrovska and Anikputa 2014).

The social foreground perspective, a more recent developmentindemographicresearch,emphasizesthe health-related resources that high-attaining children provide their elderly parents (Friedman and Mare 2014; Torssander 2013; Zimmer, Hanson and Smith 2016). Adult children with greater socioeconomic resources may be able to provide more direct care, both physical and financial, to supporttheirparents'health. Inaddition, more educated children may encourage healthier lifestyles and influence their parents' health behaviors more than less educated children. Friedman and Mare (2014), for example, find evidencethat parents'smoking and physical activity help explain the association they find between parent mortality and the educational attainments of their adultchildren.

Rather than view these as competing perspectives, we regard the long arm and social foreground perspectives as incomplete explanations of a larger multigenerational process. Regardless of the specific mechanisms, when taken together these perspectives suggest relaxing the temporal assumption of prior multigenerational models in order to allow for the possible influence of adjacent generations, $G_{1}$ and $G_{3}$. However, prior research has neither examined the degree to which $G_{1}, G_{2}$, and $G_{3}$ attainments independently contribute to $G_{2}$ longevity among older women nor considered the implications of race. Thus, a key contribution of this paper is that it considers the full multigenerational structure of mortality disparities among olderwomen and incorporatesthe complexities ofrace.

\section{Education and Opportunityin Mid-CenturyAmerica}

Studies often-but not always (e.g., Duncan et al. 2002)-observe that education has a stronger association with mortality than other common indicators of SES like occupation and income (Miech et al. 2011). The mostcommon explanations of the robust education-mortality association involve the effects of education on occupational and economic attainments and human capital development. Those with more schoolingaremore likely to gainemploymentathigherearning occupations and accumulate more wealth than their low-attaining counterparts (Mirowsky and Ross 2003). Through occupational and economic attainments, schooling is often exchanged for health advantageslike, for example, health insurance, healthier andmoreexpensivediets, and gymmemberships. With respect to more direct effects, human capital theories argue that educational attainment instills cognitive (for example, skill improvement) and noncognitive (for example, conscientiousness and a sense of mastery) resources that help reduce stress and its physical impact on the body and improve health maintenance routines and adherence to treatment regimens when illness occurs(Pampel, Krueger and Denney 2010).

Educational attainment seems fundamentally linked to survival, but, depending on its availability and economic and human capital returns, the strength of education's relationship with mortality can vary considerably across genders, races, and birth cohorts (Masters, Hummer and Powers 2012; Miech et al. 2011; Shuey and Willson 2008). Most Silent Generation women established their work and family lives well before the feminist and civil rights movements, 
meaning that they had far fewer educational and labor market opportunities than their male counterparts and more recent cohorts of women (Goldin 2006). Throughout the 1950s, when a large portion of this birth cohort of women were in their late teens and early twenties, women's college graduation rates were at historically low levels (Jacobs 1996), and the traditional gender attitudes during the formativeyears of theSilent Generation often limited women to their role in the family (see Cotter, Hermsen and Vanneman 2011). Furthermore, althoughtherates ofwomen'slaborforce participation doubled in the latter half of the century (Bureau of Labor Statistics 2016), Silent Generation womenstill had to relyheavilyonspousalattainmentsto provide key economic resources due to gendered inequalities in the labor market (Goldin 2006). Thus, the education of Silent Generation women often had little influence on their occupational and economic attainments, making their quality of lifeand, intum, their health dependent on spousal attainments (Brown, Hummerand Hayward 2014; Jacobs 1996).

\section{JimCrowand the GreatMigration}

For Silent Generation black women, institutionalized racism all but completely removed opportunities for status attainment. Most Silent Generation black women lived in the South and came of age before the end of Jim Crow. Jim Crow refers to a range of laws that legalized racial discrimination in Southem states following theend of slaveryinthelate 1800 (Woodward 2002). The enforcement of Jim Crow has been hypothesized to adversely impact health through multiplesocial mechanisms, including exposuretosocial and economic deprivation, exogenous hazards like environmental pollutants and dangerous neighborhoods, and social adversity like discrimination and relatedstressors.

The details of Jim Crow laws varied across states and over time, but they always aimed to restrict the rights of black communities while preserving the preferential treatment of white Southemers with respect to public services, especially those related to socioeconomic attainment. The public schools available to black communities in the Jim Crow South lacked the quality of those provided to white communities. Segregated schools had shorter academic years, lower pupil expenditures, and larger class sizes (Margo 1990). As a result, black populations had low rates of literacy, school attendance, and educational attainment in general. While the chances of attending college were low for this cohortofblackwomen, receiving morethan the barest public education was highly unlikely for their parents.Alargeportionoftheirparentsworkedonfarms inrural areasand received little to no formal education. In 1900 and 1910, for example, the illiteracy rate for black men in the South was 50\% and 40\%, respectively. As a point of comparison, white men had illiteracy rates of only $12 \%$ in 1900 and $9 \%$ in 1910 .

From 1910 to 1970, mounting racial tension and a lack of economic opportunities led to approximately 6 million black men and women leaving the South for major urban areas in the Midwest and Northeast of the U.S. (Tolnay 2003). These cities generally provided more educational opportunities (Margo 1990; Tolnay 2003; Waltersand James 1992) and greateraccesstothe labor market than urbanareasinthe Jim Crow South(Blacket al. 2015; Card and Krueger 1992). However, the black families thatmoved outside the South still lived in highly segregated, poorly maintained, and crime-filled neighborhoods, and the health inequalities linked to areas of concentrated poverty in cities like Chicago and NewYorkhave been noted sincethe earliestresearchon urban life in the U.S. (Fanis and Dunham 1939; Hollingshead and Redlich 1958). Thus, even though more educational and occupational opportunities existed outside the South, these opportunities may havebeenundercutbythebiological damagecaused by growing up in impoverished urban areas in the 19205 
and 1930 s.

\section{Growing Racial Equality and the Widening Education GapinMortality}

The black men and women of the Silent Generation were critical to the Civil RightsAct of 1964, for example, Martin Luther King Jr., Coretta Scott King, and Malcom $X$ were all members of the Silent Generation, but they did not benefit as much as their children did from the subsequent gains in attainment opportunities. During the latter half of the twentieth century, black communities generally experienced rising wages, an increase in the availability and quality of education, and greatereconomicreturnsfromeducation. From 1960 to 1980, for example, the wage differences between black and white men fell from 40 to $25 \%$, and Card and Krueger (1992) estimated that $20 \%$ of this narrowing is related to improvements in the relative quality of black schools. Likewise, Couch and Daly (2002) found that the equalization of educational opportunities facilitated a continued convergence of blackand white wages in the 1990s. Thus, although never on par with their white counterparts, reduced racial inequalities in education from the 1960s onward provided the children of Silent Generation women with more opportunities to becomeupwardlymobilethan previouscohortsofblack Americans.

Although growing racial equalities suggest that black and white women may receive similar returns for their children's education, research on the widening education gap in mortalitysuggests that the association between adult child education and mortality may be larger for white women. Among cohorts of white men and women, theeducational differencesinmortalityrisk have grown sharply for cohorts born in the latter half of the twentieth century (Montez andZajacova 2014). For black men and women, however, educational differences have remained relatively stable across cohorts. If a similar pattern is occurring with respect to the education of adult children and their mothers' health, then the association between adult child education and white women's mortality risk may be larger than the association for blackwomen.

On the other hand, given the importance of network ties in black communities, the increased opportunities available for their children may be an especiallyimportant resource for black women. Hogan, Hao and Parish (1990), for example, found that many blackmothers received at leastone-half of their income from individuals other than their husbands, andO'Brien (2012) found that middle- and upper-income blacks are more likely to provide informal financial assistance than their white counterparts. Thus, adult child educational attainments may provide black women with a larger proportion of their socioeconomic resources and, as a result, benefit their survival more than the survival of whitewomen.

\section{Wealthand Family Structure}

Thus far, our discussion has assumed that the educational attainments of parents and adult children provide Silent Generation women with health-related resourcesthat theywouldnototherwisehaveinlaterlife. It is possible, however, that any observed relationships between multigenerational attainments and mortality aretheresultofunderlying social and psychological traits that shape both longevity and family-level resources. Although adjusting for every possible confounder is impossible, prior research suggests that wealth and family structure are key determinants of health that could also create spurious associations between multigenerational attainmentsand mortality.

Indicators of economic attainment offer direct assessments of one's ability to purchase resources like private health insurance, expensive medications and treatments, and living spaces without toxins or 
carcinogens. Like education, long-term measures of economic attainment provide an approximation of personal traits like intellectual abilities and noncognitive skills like discipline that help amass wealth and protect health (Hällsten and Pfeffer 2017). With respect to multigenerational attainments, wealth often includes the financial and material successes of previous generations and increases the chances of educational and occupational attainments of future generations (Mare 2011). Furthermore, wealth captures the accumulated impact of racial inequalities in economic opportunities over the course of multiple familial generations (Oliver and Shapiro 1995). Even by the late 1980 s and early 1990s, for example, the median net worth ofblack families was less than $10 \%$ of what white families reported, and the majority of black families had nowealthorwereindebt.

Family structure might also explain associations between multigenerational attainments and mortality. On one hand, marriage can provide a source of emotional, social, and economic support that improves physical and mental health (Carrand Springer 2010). On the other hand, marital dissolution through divorce and widowhood appears to damage health and longevity through its negative impact on families' emotional and economic wellbeing. Furthemore, divorce, which occurs at a higher rate among black men and women (Sweeney and Phillips 2004), may also reduce children's educational attainment(Bernardiand Radl 2014).

\section{DATAAND METHODS}

The analysis used mortality information from the NLSNDI matched dataset that includes recently updated information on mortality for the National Longitudinal Survey of Mature Women (NLS-MW). The NLS-MW began in 1967with a nationallyrepresentative sampleof 5,083 noninstitutionalized women between the ages of 30 and 44 . Information is available from 20 follow-up interviews that occurred between 1968 and 2003. The mortality information we used comes from data collection through the Demographic Survey Division (DSD) of the United States Census Bureau (USCB) and the National Center on Health Statistics (NCHS), which has a complete database of all death records provided directlyby thestate agencies and contains SSN, firstand lastnames, birth date, sex, and race.Thus, theNLS-MW datahas highlyaccurate mortality data.

Thefinal analysis sample was limited to 2,432 white and 917 black respondents $(\mathrm{N}=3,349)$ who had adult children (25 or older) in the 1977, 1986, 1999, or 2003 waves. The 1977 wave (10 years past baseline) was the first year the NLS collected information on the educational attainment of adult children. We therefore began with the 1977 sample $(\mathrm{N}=3,907)$ and updated adult child education using the 1986, 1997, and 2003 waves. Respondents who did nothave a child reach the age of 25 by the final wave were dropped from the analysis ( $\mathrm{N}=556)$, leaving a sample size of 3,351. In supplemental analyses, we found no evidence of racial differencesintheodds of having achild whoreached the age of $25(95 \% \mathrm{Cl}=.80,1.19)$. Two additional cases were dropped because their age of death was younger or equal to their age in 1977. This left the final sample of 3,349 women. All data preparation and analyses were conducted using Stata 15.1 (StataCorp 2017), and the code to replicate the analysis is maintained at a publicly available website to facilitate extensions to this study ([identifying linkomitted]).

Missing data were addressed using multiple imputation with chained equations as implemented in Stata's MI suite of commands to construct 20 complete datasets. Overall rates of missing data were low with most variables, having either no missing dataormissing forlessthan $1 \%$ of respondents. Theprimary exceptions were parents' education and occupation, which were missing for $16.9 \%$ and $8.8 \%$ of respondents, respectively. Diagnostictestsindicated that the imputed 
values for these measures tended towards lower levels of education and occupation scores than in the original distributions, but ultimately the imputed values did not substantiallyshift distributions(Eddingsand Marchenko 2012).

\section{Variables}

Mortality. Respondents' age at entry into the risk set ranged from 40 to 54 (see Table 1) with a median age of approximately 48 for the white sample and 47 for the blacksample.By2012,43\%ofthesamplewas deceased with an estimated median age of death of 85 years old. This varied byrace, though. A much largerproportion of the black sample was deceased by 2012, .53 compared to 39 for the white sample, and the estimated median age of death among whites was 87 and only 81 for the blacksample.

--Table 1abouthere--

Because each generation usually included multiple members - mother/father, respondent/spouse, and two or more children-we combined attainment information in meaningful ways in order to create variables that broadly characterize the attainment of each generation. Because spousal attainment was critical to the quality of life for this cohort of women and their mothers (see our prior discussion of the inequality of attainment opportunities in the mid-twentieth century), we used the head of household attainment when respondents were adolescents, typically their father, to create parent attainment, and we used the highest level of education and occupation among respondents and their spouses to create personal/spousal attainment. For adult children, we used the attainment of the highest educated child, an approach used in prior examinations of the social foreground (Torssander 2014). Other measures of children's attainment, the proportion of children with a certain educational level or the education of the firstborn, for example, have previously been compared and found to yield similar results (Torssander 2013). To check the sensitivity of results, supplemental analyses considered several other operationalizations of multigenerational attainments, including models that separated spouse and respondent attainment (see online appendix). These alternative operationalizations supported the same conclusions that are presented here.

Educational Attainment. Educational attainment was operationalized as a three or four category variable created from meaningful educational thresholds within the historical context of each generation. Parents' educational attainment wasoperationalized as(1)o to 6 years, (2)7to 11 years, and (3) 12 or more years. Forboth white and black women, far fewer of their parents completed high school and went to college than did future generations (see Table 1). This was not surprising given that their parents grew up when public education was just beginning to spread across the U.S. As education became more important for success in the U.S. labor market, the average years of schooling increased. However, the rise in educational attainment disproportionally favored white women and men. To reflect this trend, personal/spousal education was measured as (1) o to 11 years, (2) 12 years, (3) 13 to 15 years, and (4) 16 or more years for white women. For black women, personal/spousal education was measured as (1) o to 11 years, (2) 12 years, and (3) 13 or more years. We did not indude a fourth category for black women because only 64 black women or their spouses in our final sample attained 16 ormore years of education. Cohorts following the Silent Generation experienced an even greater expansion of education. Thus, adult children's attainment was measured as (1) 0 to 12 years, (2) 13 to 15 years, (3) 16 years, and (4) 17 or 
more years. Models that induded adult attainment also control for respondents' total number of children, the gender of respondents' most educated child, and the year information was collected about adult children (1977, 1986, 1999, or 2003).

Occupational Attainment. Due to the limited opportunities for educational attainment among the parents of the NLS-MW women and the women themselves, occupation was also used as an additional indictor of socioeconomic status. Parents' occupational attainment were measured as categories that included manual (private household, senvice, operators, transportation, or laborers), farming (farmers and farm managers), skilled (technical and related support, sales, administrative support, protective senvices, or the military), and white-collar (managenial or professional occupations). The same set of occupations was created for respondents with the exception of farming, which only a small number of respondents reported. Unfortunately, theNLS-MW did not collect information on the occupations of women's adultchildren.

Wealth. The final model included a measure of averagefamily wealth, which was constructed bytaking the average of women's wealth from the 1967, 1971, 1972, 1977, 1982, 1987, 1989, 1995, 1997, 1999, and 2001 surveys for respondents 65 and younger in the given year. Tocreatetotal netassets, theNLStakesthesum of women's housing, savings, bond, IRA, insurance, and business assets and then subtracts mortgages, loans, and other debts (excluding automobile wealth). A small number of respondents $(N=265)$ had a negative average, which was recoded to o. Before imputation, respondents' wealth was converted to 2016 dollars, logged, standardized, and outliersweremoved closerto the center mass of the distribution (within three standard deviations of the mean). In supplemental analyses, we also considered variation in average wealth, average family income, variation in family income, and a measure of wealth that adjusted for married couples. Resultsled to thesame conclusionswe presenthere (see online appendix).

Sociodemographic Controls. Every model in the analysis controls for a number of important factors related to multigenerational attainments and mortality (seeTable 1). First, family structure atage 15 is defined as living with both biological parents or living in some other family structure. Second, marital history is measured as an indicator of whether respondents ever expenienceda divorce. Marital status was measured as a simple binary because a majority of the NLS-MW remained mamied throughout the survey, and virtually none of the sample remained unmamied ( $\mathrm{N}=4$ for the white sample and $\mathrm{N}$ $=43$ for black sample). Finally, models control for whether the respondents lived in the South.

\section{Methods}

Forthenextstep intheanalysis, we used amodeling and postestimation strategy that was meant to identify the associationsbetweeneachgeneration'sattainmentand mortality and the degree to which those associations were robust to the inclusion of other generations' attainments and controls. First, we began with a descriptive analysis of how socioeconomic attainments vary across generation and race. Next, we estimated a series of Gompert hazards models that examine the associations between parent, personal/spousal, and adult children's attainments and mortality separately before fitting a model that included the attainments of all three generations and a final model that adjusted for family wealth (see online appendix for a more detailed discussion of our methods and companisons with semiparametric Coxmodels).

The analysis was stratified by race, but we also fit auxiliary models on the full sample that included interaction terms between race and each measure of 
attainment to test racial differences (see online appendix). To consider the relative importance of adjacent generations in the overall multigenerational structure of $\mathrm{G}_{2}$ mortality by race, we also predicted median ages of death using different values of parent and adult child attainments with Stata's margin command (StataCorp 2017). Standard errors and confidence intervals for the median ages of death were calculated using the delta method. Statistical tests for the attenuation of coefficients across models were conducted using Stata'ssuest command.

\section{RESULTS}

Figure 1 illustrates baseline predicted survival curves by race, educational attainment, and generation. The first two panels show respondent curves by parental educational attainment. Although differences are relatively small, each curve for white women is discernable and suggests an improvement in mortality riskwitheach increase ineducational category. Forblack women, however, the survival curves related to their parents' education are nearly overlapping. In the middle row of Figure 1 , the survival curves related to personal/spousal education are more distinct for white women, whereasthecurvesforblackwomenarenearly identical for the o to 11 years of schooling category and the 12years of schooling categoryand showamoderate differenceinsurvival forthe 13 ormore years of schooling category. In contrast to parent and personal/spousal attainments, the education of women's adult children shows asimilar relationship to blackand white women's survival, with the smallest difference occuming between the 13 to 15 and 16 years of schooling categories and the largest difference occuming between the o to 12 and the 17ormore years of schooling categories.

--Figure1abouthere--
Table 2 presents results from Gompert hazards models for white women. The attainments of all three generations were initially associated with white women'smortalityrisk. InModel 1, we found thathaving parents with 12 or more years of education and parents whowere farmers wereassociated with a $20 \%$ and $18 \%$ reduction ( $95 \% \mathrm{Cls}=.64, .98$ and $.68, .98$ respectively) in the hazard of mortality, respectively. In Model 2, 16 or more years of schooling and white-collar occupations were associated witha $34 \%$ and $20 \%$ reduction ( $95 \% \mathrm{Cls}$ $=.52, .85$ and $.66, .97$ respectively) in the hazard of mortality, respectively. In Model3, we observed roughly the same association with adult child schooling and the hazard of mortality increased from a $23 \%$ reduction toa $47 \%$ reduction $(95 \% \mathrm{Cls}=.65, .93$ and $.44, .64$ respectively) across higher levels of schooling. The associations between $G_{1}$ and $G_{2}$ educational attainments and $G_{2}$ mortality risk were reduced to nonsignificance in Models 4 and 5 . Each of the changes observed in the coefficients for parent and personal/spousal education from their baseline associations in Models 1 and 2, respectively, to Models 4 and 5 in Table 2 were significant at the .05 level or lower (see onlineappendixformodelcomparisons). However, even after controlling for wealth and the attainments of all three generations in Model 5, adult child education was related to a significantly lower mortality risk among older women, ranging from a $18 \%$ reduction $(95 \% \mathrm{Cl}=$ $.68, .99)$ for 13 to 15 years of schooling to $41 \%$ reduction $(95 \% \mathrm{Cl}=.48, .74)$ for 17 or more years of schooling.

--Table 2 abouthere--

Table 3 presents results for black women. Like the white sample, black women's survival provided support for a multigenerational process in which aspects of $G_{1}$, $\mathrm{G}_{2}$, and $\mathrm{G}_{3}$ socioeconomic attainments were independently associated with $G_{2}$ mortality risk. In Model 1, we observed a similar association for parent 
farming as with white women-having parents who werefarmerswasassociated with a 20\% reduction( $95 \%$ $\mathrm{Cl}=.65$, .99) in the hazard of mortality. Similarly, inModel 3 , having more education adultchildren was associated with a $26 \%$ and $53 \%$ reduction( $95 \% \mathrm{Cls}=.57, .96$ and .34 , .64 respectively) in the hazard of mortality for 16 years of schooling and 17 or more yearsof school, respectively.

In contrast to white women, parent and personal/spousal educational attainments were not significantly associated with black women's mortality in any model. With respecttoGz attainment, however, we found a robust relationship between education and black women's mortality. In analyses not shown, we tested racial differences in the relationships between multigenerational attainments and mortality with interactions between race and education (see online appendix). Overall, those results supported the conclusion that parent, personal, and spousal educational attainments provided a greater advantage for the survival of white women. With respect to adult children, however, this trend was not observed. That is, the association between adult child educational attainment and mortality did not significantly differ between blackand whitewomen.

--Tablezabouthere--

In Figure 2, we provide an illustration of the substantive effect sizes of the associations between adjacent generations and survival by comparing the predicted median ages of death for white and black women by category of parent occupation and adult child education. These predictionswere calculated using coefficients from a reduced Gompertz hazard model with interactions between race and parent occupation, adult child education, family wealth, and sociodemographic controls (estimates available at online appendix). The dashed lines in the figure represent the unadjusted medians for the white and black samples at 87 and 81 , respectively. For parents' attainment, the largest inequalities in women's survival occurred among the children of skilled and manual workers (approximately 8 and 4 years, respectively), whereas the children of farmers had the smallest racial differences in median age of death at 3 years $(95 \% \mathrm{Cl}=$ .74, 5.8). In terms of adult children's education, the smallest racial inequality in survival was among the mothers of high achievers, a difference of only 3.6 years $(95 \% \mathrm{Cl}=-.15,7.35)$ between white and black women who had children with 17 or more years of schooling.

--Figure 2 abouthere --

\section{DISCUSSION}

An emerging literature suggests that the socioeconomic attainments of parents and adult children may provide an array of life-extending resources in old age. However, research has neither tested whether this multigenerational structure exists in mortality disparities for women nor considered the impact of race. Using data from the National Longitudinal Survey of Mature Women, we find evidence of (1) a multigenerational model in which aspects of $G_{1}, G_{2}$, and $G_{3}$ attainments are independently linked to $G_{2}$ survival among both black and white Silent Generation women and (2) racial differences in the associations between $G_{1}$ and $G_{2}$, but not $G_{3}$, educational attainments and $G_{2}$ mortality. Results from the analysis were broadly consistent with prior researchand move the literatureforward in several ways. Below, we discuss our key findings, notable limitations of the data and analysis, and the broader implications of thecurrentstudy forfuture research.

\section{Keyfindings}

First, the analysis found evidence of a three-generation model in which parent, personal/spousal, and adultchild 
attainments were linked to the survival of Silent Generation women. Results from Gompert proportional hazards models suggested that having parents who were farmers, accumulating greater wealth, and having high-attaining adult children all independently reduced mortality risk among older women, regardless of race. Even after adjusting for wealth and sociodemographic controls, our final model predicts that those with higher multigenerational attainments will live significantly longer, suggesting that the flexible resources linked to the attainments of adjacent generations are potentially quite consequential. Thus, consistent with the long arm and social foreground perspectives, our results support relaxing the unidirectional nature of prior multigenerational models to identify the full extent of healthdisparitiesamong olderpopulations of women.

Second, with respect to the long arm perspective, results support prior studies that have found living on farms or in rural areas reduces one's mortality hazard in adulthood (Warner and Hayward 2006). The NLS-MW were borm between 1923 and 1937, which means these women were bom immediately prior or during the Great Depression. Farming in this period was common, and while they did not avoid the financial repercussions of the Great Depression, farmers were in a much better position to grow food for their families when malnutrition was believed to be widespread among children(Watkins2000). Growing uponfarmsmayhave also reduced women's exposure to pervasive air and waterpollution in urban areas priorto federal policies like the Air Pollution Control Act of 1955, and even though the biological pathways remain undear, recent studies still find that farming communities have lower rates of a number ofhealthissues, especially respiratoryproblems (Stein etal. 2016).

Third, with respect to the social foreground perspective, we find that the schooling of adult children had a robust association with both white and black women's mortality. Thisresult providesfurtherevidence that the socioeconomic attainments of adult children are related to lifeexpectancy(Friedman and Mare 2014; Torssander 2013; Torssander 2014; Zimmer, Hansonand Smith 2016). The social foreground's inversion of the more commonly studied intergenerational transmission processes represents an important shift in thinking for researchers, especially as the U.S. experiences a dramatic increase in the population of older adults in the coming years (Ortman, Velkoff and Hogan 2014).

Fourth, we found racial differences in the associations between parent and personal/spousal educational attainments and mortality but not in the association between adult child education and mortality. In models that considered generations separately, parent and personal/spousal education had significantly largerassociations with the survival of white women compared to black women, which is consistent with prior research (Kelley-Moore and Huang 2017; Shuey and Willson 2008). However, our work went a step further by examining adult children's education, which wasanequallyrobust predictor ofblackand white women's survival. Thus, the education of their children maysupplySilentGenerationblackwomen with healthrelated resources that theirowneducation, in additionto the educational attainments of their parents and spouses, did not provide.

Related, even though the children of Silent Generation black women had greater access to attainment structures than their mothers, substantial racial inequalities in educational and labor market outcomes still existed. In our sample, for example, the most educated child of $39 \%$ of black women had 12 or fewer years of schooling, compared to only $26 \%$ of whitewomen. Furthermore, theestimatedmedianage of life for black women who had children with 12 or fewer years of education was younger than all other estimates, including black women's unadjusted median 
age of death. Thus, the black women who had the weakest familial safety nets with respect to socioeconomic attainment were also those who died at theyoungestages.

\section{Limitations}

Ourstudy is unique in its ability to examine the effects of multigenerational attainments on women's mortality, but our findings are limited in ways that provide future opportunities for research. First, the NLS-MW does not contain information on the economic attainment of parents or theeconomicoroccupational attainments of adult children. While having parents who farmed was related to a reduction in mortality hazard, parents' longterm economic circumstances would have likely provided a better indicator of women's childhood conditions. Forexample, using family incomein addition to occupational and educational information, Pudrovska (2014) found a robust association between parentSES and mortality. However, this association did attenuate as the population aged. Thus, the relatively weak association between parents' attainment and women's mortality may be the result of an insufficient measure of economic circumstances or the diminishing effectofchildhoodSES as thepopulationages.

Second, this study finds a robust relationship between adult child schooling and mortality, but itdoes not examine intervening mechanisms or address all potential confounders. Torssander (2013) addressed some of the potential concerns regarding a causal interpretation by using family fixed effects models, which reduces the influence of unobserved family characteristics, and we controlled for family wealth and family structure throughout one's life course. Nevertheless, unobserved variation maystill accountfor this association, and elucidating the causal mechanisms and addressing endogeneity within families are important next steps for research. For example, adult children's education might be capturing the association between survival and mother's unobserved human capital or family characteristics that neither parental nor personal/spousal attainments fully capture. Likewise, parents who value education and/or seek to help their children becomeupwardlymobileare oftentheproduct of similar family expectations and circumstances. In other words, which children-and grandchildrenattain more is not random (Song and Mare 2017). Unobserved characteristics of women and families like this may also be related to women's health, and although this point does not necessarily contradict the social foreground hypothesis, it does suggest that future research should clarify the dynamic interplay between generational attainments, family and parent characteristics, and health.

\section{ImplicationsforScholarship and Future Research}

Despite these limitations, our findings have important implications for scholarship and future research in several areas. First, given the shifting impact of gender, race, and education on life chances across the twentieth century, health disparities scholarship comparing cohorts should consider multiple sources of status. For women in the Silent Generation, and black women in particular, many of the flexible resources related to health were inaccessible by way of personal attainment due to the systematic lack of opportunity to achieve academicallyortoexchangeacademicachievementfor economic returns in the labor market (Goldin 2006; Jacobs 1996). Thus, to identify the full extent of health disparities among populations with few opportunities for personal attainment, future research should continue examining the relationship between family attainmentand health.

Second, our findings also have implications for research examining social relationships and health in later life. Close relationships and strong social networks 
among older adults are related to health and longevity (Comwell and Waite 2009; Umberson 2017), but functional dedine and the accompanying increase in household disorder, including general household disrepair, clutter, lack of cleanliness, odor, and noise, in the dwellings of older adults are related to a reduction in network size, number of friends, social support, and social interactions (Cornwell 2016; Schafer 2018). Older adults are also more likely to lose close relationships through death, especially black women, which can be emotionally devastating and socially isolating (Umberson 2017). This area of research suggests that visits tohelpelderly familymembers withsmall tasks like cleaning around the house and transportation to social activities could help reduce their social isolation and improve the health of elderly populations. However, because the U.S. is currently undergoing a dramatic increase in the population of older adults (Ortman, Velkoff and Hogan 2014) and more recent cohorts of women are generally providing fewer hours of informal carework (Pavalko andWolfe 2016), social isolation and its consequences are likely to grow among elderly populations, especially among disadvantaged groups with lessstable social networks (Comwell 2015). Thus, to better detect vulnerable populations, future research in this area should consider incorporating the socioeconomic attainments of kin networks into models of aging, social isolation, and health.

Third, our findings suggest that future studies of SES and health across the life course mightbenefitfrom additional information on the socioeconomic resources of family members when studying older populations. Personalattainmentsmaybepoorindicatorsofmaterial and social circumstances in later life when people begin to rely more heavily on assistance from family. During this period of the life course, the weakening of theSEShealth association that studies often observe (e.g. Brown et al. 2016) may in part reflect a decoupling of personal attainments from material circumstances as exogenousfactors beginto have anincreased impacton quality of life and health due to the economic and physical vulnerability of older populations. Thus, measures of socioeconomic resources that include multigenerational attainments might be necessary to fully identify socioeconomic inequalities in older populations.

Finally, our findings have implications for future research on racial inequalities in asset accumulation and health. Broadlyspeaking, theassociation betweenadult children's education and women's survival we found in the analysis was similar forblack and white women, but the current study did notelaborate on racial inequalities in the lives of black children and what that might mean for their parents' health. High-attaining children generally come from similarly high-attaining parents (Torche 2011), but unlike their white counterparts, highattaining black children often provide financial assistance to family and friends due to the disadvantaged nature of their networks (O'Brien 2012) —what Portes(1998)calls "negative social capital." Successful white children are frequently embedded in advantaged networks that rarely need financial or instrumental support until much later in life, which frees future generations to accumulate personal assets, like purchasing a home or building an investment portfolio, as soon as they enter the labor market. For successful black children, however, giving financial assistance to their networks, while beneficial for family and friends, is yet another obstacle in gaining financial stability and wealth and avoiding debt (Conley 1999; Killewald, Pfeffer and Schachner 2017; Oliver and Shapiro 1995). When considered with our results, this suggests that institutional racism in a focal generation's attainment directly affects their health and mortality in adulthood (PhelanandLink2015; Williams2012)and thenindirectly inold ageastheupstreameffectofracism constrainsthe ability of high-attaining black children to accumulate wealth and, in turn, reduces the overall resources 
available to elderly black populations. Thus, social policies aimed at improving educational opportunities for black youth and asset accumulation among young black adults could offer potential, though indirect, paths to reducing racial inequalities in survival among elderly populations.

\section{SUPPLEMENTAL MATERIAL}

The Appendix is available in the online version of the article.

\section{AUTHORS'NOTE}

Previous versions of this paper were presented at the annual meetings for the American Sociological Association, Intemational Sociological Association, and in the departments of Sociology and Human Developmentand FamilyStudiesatPurdueUniversity.

\section{ACKNOWLEDGMENTS}

The authors are grateful to the anonymous JHSB reviewers and the editor, Dr. Richard Carpiano, for providing invaluable feedback during the revision process.

\section{REFERENCES}

Almond, Douglas, and Janet Cumie. 2011. "Killing Me Softly: The Fetal Origins Hypothesis." Joumal of Economic Perspectives 25(3):153-72.

Alwin, Duane F., and Ryan J. McCammon. 2003. "Generations, Cohorts, and Social Change." Pp. 2349 in Handbook of the Life Course, edited by JeylanT. Mortimer and Michael J. Shanahan. New York: KluwerAcademic/PlenumPublishers.

Bernardi, Fabrizio, and Jonas Radl. 2014. "The LongTerm Consequences of Parental Divorce for Children's Educational Attainment." Demographic Research30:1653-80.
Black, DanA.,Seth G. Sanders, Evan J. Taylor, and Lowell J. Taylor. 2015. "The Impact of the Great Migration on Mortality of African Americans: Evidence from the Deep South." American Economic Review 105(2):477-503.

Brown, Dustin C., Robert A. Hummer, and Mark D. Hayward. 2014. "The Importance of Spousal Education for the Self-Rated Health of Maried Adults in the United States." Population Research and Policy Review33(1):127-51.

Brown, Tyson H., Liana J. Richardson, Taylor W. Hargrove, and Courtney S. Thomas. 2016. "Using Multiple-Hierarchy Stratification and Life Course ApproachestoUnderstand Health Inequalities:The Intersecting Consequences of Race, Gender, Ses, and Age." Joumal of Health and Social Behavior 57(2):200-22.

Bureau of Labor Statistics. 2016. U.S. Department of Labor, Occupational Employment Statistics. Accessed on July 22, 2016. mww.bls.gov/oes/.

Card, David, and Alan B. Krueger. 1992. "School Quality and Black-White Relative Earnings: A Direct Assessment." The Quarterly Joumal of Economics 107(1):151-200.

Carr, Deborah, and KristenW.Springer.2010."Advances in Families and Health Research in the 21st Century." Joumal of Mamiage and Family 72(3):74361.

Conley, Dalton. 1999. BeingBlack, Livinginthe Red: Race, Wealth, and Social Policy in America. Berkeley and LosAngeles:Univ ofCalifomiaPress.

Cornwell, Benjamin. 2015. "Social Disadvantage and Network Turnover." Joumals of Gerontology, Series B: Psychological Sciences and Social Sciences 70(1):132-42.

Cornwell, Erin York. 2016. "Household Disorder, Network Ties, and Social Support in Later Life." Joumal of Mariage and Family $78(4): 871-89$. 
Cornwell, Erin York, and Linda J. Waite. 2009. "Social Disconnectedness, Perceived Isolation, and Health among Older Adults." Joumal of Health and Social Behavior 50(1):31-48.

Cotter, David, Joan M. Hermsen, and ReeveVanneman. 2011. "The End of the Gender Revolution? Gender RoleAttitudes from 1977to 2008." American Joumal ofSociology117(1):259-89.

Couch, Kenneth, and MaryC. Daly. 2002. "Black-White Wage Inequality in the 1990s: A Decade of Progress." Economic Inquiry40(1):31-41.

Duncan, Greg J., MaryC. Daly, Peggy McDonough, and David R. Williams. 2002. "Optimal Indicators of Socioeconomic Status for Health Research." AmericanJoumal of Public Health 92(7):1151-57.

Eddings, Wesley, and Yulia Marchenko. 2012. "DiagnosticsforMultiplelmputationinStata."Stata Joumal 12(2):353-67.

Elder, Glen H., and LindaK. George. 2016. "Age, Cohorts, and the Life Course." Pp. 59-85 in Handbook of the Life Course: Volume li, edited by J. Michael Shanahan, T. Jeylan Mortimer, and Monica Kirkpatrick Johnson. Cham: Springer International Publishing.

Faris, RobertE.L., and H.WarrenDunham. 1939.Mental Disorders in Urban Areas: An Ecological Study of Schizophrenia and Other Psychoses. Chicago: UniversityofChicagoPress.

Friedman, Esther M., and Robert D. Mare. 2014. "The Schooling of Offspring and the Survival of Parents." Demography 51(4):1271-93.

Goldin, Claudia. 2006. "The Quiet Revolution That Transformed Women's Employment, Education, and Family." The American Economic Review 96(2):1-21.

Hällsten, Martin, and Fabian T. Pfeffer. 2017. "Family Wealth and Grandchildren's Educational Achievement in Sweden." American Sociological Review82(2):pp.328-6o.
Hayward, Mark, and Bridget K. Gorman. 2004. "The Long Arm of Childhood:The Influence of Early-Life SocialConditionson Men's Mortality." Demography 41:87-107.

Ho, Jessica Y., and Andrew Fenelon. 2015. "The Contribution of Smoking to Educational Gradients inU.S. Life Expectancy." Joumal of Health and Social Behavior 56(3):307-22.

Hogan, Dennis P., Ling-Xin Hao, and William L. Panish. 1990. "Race, Kin Networks, and Assistance to Mother-Headed Families." Social Forces 68(3):797812.

Hollingshead,A.B., and FrederickC. Redlich. 1958. Social Class and Mental Illness: A Community Study New York:Wiley.

Huang, Jonathan Y., Amelia R. Gavin, Thomas S. Richardson, Ali Rowhani-Rahbar, David S. Siscovick, etal. 2015. "Are Early-LifeSocioeconomic Conditions Directly Related to Birth Outcomes? Grandmatemal Education, Grandchild Birth Weight, and Associated Bias Analyses." American Joumal of Epidemiology182(7):568-78.

Hummer, Robert A., and Joseph T. Lariscy. 2011. "Educational Attainment and Adult Mortality." Pp. 241-61 in International Handbook of Adult Mortality, edited by Richard $\mathrm{G}$. Rogers and Eileen $\mathrm{M}$. Crimmins: SpringerNetherlands.

Jacobs, Jerry A. 1996. "Gender Inequality and Higher Education."Annual Review of Sociology 22:153-85.

Kelley-Moore, Jessica A., and Wenxuan Huang. 2017. "The "GoodTimes" Cohort in Later-Life." Research onAging 39(4):526-48.

Killewald, Alexandra, Fabian T. Pfeffer, and Jared N. Schachner. 2017. "Wealth Inequality and Accumulation." Annual ReviewofSociology 43:35.135.26.

Lê-Scherban, Félice, Ana V. Diez Roux, Yun Li, and Hal Morgenstern. 2014. "Associations of Grandparental Schooling with Adult Grandchildren's Health 
Status, Smoking, and Obesity." American Joumal of Epidemiology $180(5): 469-81$.

Mare, Robert D. 2011. "A Multigenerational View of Inequality." Demography48(1):1-23.

-. 2014. "Multigenerational Aspects of Social Stratification: IssuesforFurther Research." Research in SocialStratification andMobility35:121-28.

Margo, Robert A. 1990. "Race and Schooling in the South:AReview of the Evidence."Pp. 6-32 in Race and Schooling in theSouth, 1880-1950:An Economic History, edited by Robert A. Margo. Chicago: UniversityofChicagoPress.

Masters, Ryan K., Robert A. Hummer, and Daniel Powers. 2012. "Educational Differences in U.S. Adult Mortality: A Cohort Perspective." American Sociological Review77:548-72.

Miech, Richard, Fred Pampel, Jinyoung Kim, and RichardG. Rogers. 2011. "The EnduringAssociation between Education and Mortality: The Role of Widening and Narrowing Disparities." American Sociological Review76(6):913-34.

Mirowsky, John, and CatherineE. Ross. 2003. Education, Social Status, and Health. New York: Aldine De Gruyter.

Montez, Jennifer K., and Anna Zajacova. 2013. "Explaining the Widening Education Gap in Mortality among U.S. White Women." Joumal of Health and SocialBehavior 54(2):166-82.

-. 2014. "Why Is Life Expectancy Dedining among Low-Educated Women in the United States." AmericanJoumal of Public Health 104(10):e5-e7.

O'Brien, Rourke L. 2012. "Depleting Capital? Race, Wealth, and Informal Financial Assistance." Social Forces 91(2):375-95.

Oliver, Melvin, and Thomas M. Shapiro. 1995. Black Wealth/White Wealth: A New Perspective on Racial Inequality. NewYork: Routledge.

Ortman, Jennifer M., Victoria A. Velkoff, and Howard Hogan. 2014. "An Aging Nation: The Older
Population in the United States." in Population Estimates and Projections: U.S.CensusBureau.

Pampel, Fred C., Patrick M. Krueger, and Justin T. Denney. 2010. "Socioeconomic Disparities in Health Behaviors." Annual Review of Sociology 36:349-70.

Pavalko, Eliza K., and Joseph D. Wolfe. 2016. "Do Women Still Care? CohortChanges inUsWomen's Care for the Ill or Disabled." Social Forces 94(3):135984.

Phelan, Jo C., and Bruce G. Link. 2015. "Is Racism a Fundamental Cause of Inequalities in Health?" Annual Review of Sociology 41(1):311-30.

Portes, Alejandro. 1998. "Social Capital: Its Origins and Applications in Modern Sociology." Annual Review ofSociology24(1):1.

Pudrovska, Tetyana. 2014. "Early-Life Socioeconomic Status and Mortality at Three Life Course Stages: An Increasing within-Cohort Inequality." Joumal of HealthandSocialBehavior 55(2):181-95.

Pudrovska, Tetyana, and Benedicta Anikputa. 2014. "Early-Life Socioeconomic Status and Mortality in Later Life: An Integration of Four Life-Course Mechanisms." Joumals of Gerontology, Series B: PsychologicalSciences and SocialSciences69(3):45160.

Schafer, Markus H. 2018. "(Where) Is Functional Decline Isolating? Disordered Environments and theOnset of Disability." Joumal of Health and Social Behavior 59(1):38-55.

Shuey, Kim M., and Andrea E. Willson. 2008. "Cumulative Disadvantage and Black-White Disparities in Life-Course Health Trajectories." Research onAging30:200-25.

Song, Xi, and Robert D. Mare. 2017. "Short-Term and Long-TermEducational Mobility ofFamilies:ATwoSexApproach." Demography 54:145-73.

StataCorp. 2017. Stata Statistical Software: Release 15. CollegeStation, TX:StataCorpLP. 
Stein, Michelle M., Cara L. Hrusch, Justyna Gozdz, Catherine Igartua, Vadim Pivniouk, et al. 2016. "Innate Immunity and Asthma Risk in Amish and Hutterite Farm Children." New England Joumal of Medicine 375(5):411-21.

Sweeney, Megan M., and Julie A. Phillips. 2004. "Understanding Racial Differences in Marital Disnuption: Recent Trends and Explanations." Joumal of Marriage and Family 66:639-50.

Tolnay, Stewart E. 2003. "The African American "Great Migration" and Beyond." Annual Review of Sociology2g(1):209-32.

Torche, Florencia. 2011. "Is a College Degree Still the Great Equalizer? Intergenerational Mobility across Levels of Schooling in the United States." American Joumal of Sociology 117(3):763-807.

Torssander, Jenny. 2013. "From Child to Parent? The Significance of Children's Education for Their Parents'Longevity." Demography 50(2):637-59.

—. 2014. "AdultChildren's Socioeconomic Positions and Their Parents' Mortality: A Comparison of Education, Occupational Class, and Income." Social Science\&Medicine 122:148-56.

Umberson, Debra. 2017. "Black Deaths Matter: Race, Relationship Loss, and EffectsonSunvivors." Jourmal of HealthandSocialBehavior 58(4):405-20.

Walters, Pamela B. , and David R. James. 1992. "Schooling for Some: Child Labor and School Enrollment of Black andWhiteChildren in the Early Twentieth-Century South." American Sociological Review 57:635-50.

Warner, David F., and Mark D. Hayward. 2006. "EarlyLife Origins of the Race Gap in Men's Mortality." Joumal of Health and SocialBehavior 47:209-26.

Warren, John Robert, and Robert M. Hauser. 1997. "Social Stratification across Three Generations: New Evidence from the Wisconsin Longitudinal Study." American Sociological Review 62:561-72.
Watkins, T.H. 2000. The HungryYears:ANarrative History of the GreatDepressioninAmerica. NewYork: Henry Holtand Company, LLC.

Williams, David R. 2012. "Miles to Go beforeWe Sleep: Racial Inequities in Health." Joumal of Health and Social Behavior 53(3):279-95.

Wolfe, Joseph D., Shawn Bauldry, Eliza K. Pavalko, and Mellissa A. Hardy. 2018. "Multigenerational Attainment and Mortality among Older Men: An Adjacent Generations Approach." in Population Assocation ofAmerica. Denver, CO.

Woodward, C. Vann. 2002. The Strange Career of Jim Crow.NewYork: OxfordUniversityPress.

Zimmer, Zachary, Heidi A. Hanson, and Ken R. Smith. 2016. "Offspring Socioeconomic Status and Parent Mortality within a Historical Population." Demography 53:1583-603. 
Table 1. Descriptive Statistics for Analysis Variables

\begin{tabular}{|c|c|c|c|c|}
\hline & \multirow[b]{2}{*}{ Min } & \multirow[b]{2}{*}{ Max } & \multirow{2}{*}{$\begin{array}{l}\text { White Sample } \\
(\mathrm{N}=2,432) \\
\begin{array}{c}\text { Median or } \\
\text { Proportion }\end{array}\end{array}$} & \multirow{2}{*}{$\begin{array}{c}\begin{array}{c}\text { Black Sample } \\
(\mathrm{N}=917)\end{array} \\
\text { Median or } \\
\text { Proportion }\end{array}$} \\
\hline & & & & \\
\hline Age at entry into risk set & 40 & 54 & 48 & 47 \\
\hline Age at death & 45 & 90 & 87 & 81 \\
\hline Deceased by 2012 & 0 & 1 & 0.39 & 0.53 \\
\hline \multicolumn{5}{|l|}{ Multigenerational attainments } \\
\hline \multicolumn{5}{|l|}{ Parent schooling } \\
\hline o to 6 & o & 1 & 0.16 & 0.41 \\
\hline 7 to 11 & 0 & 1 & 0.48 & 0.44 \\
\hline 12 or more & o & 1 & 0.36 & 0.15 \\
\hline \multicolumn{5}{|l|}{ Parent occupation } \\
\hline Manual labor & 0 & 1 & 0.36 & 0.53 \\
\hline Farming & 0 & 1 & 0.21 & 0.37 \\
\hline Skilled & 0 & 1 & 0.18 & 0.10 \\
\hline White collar & 0 & 1 & 0.19 & -- \\
\hline \multicolumn{5}{|l|}{ Personal/spousal schooling } \\
\hline o to 11 & 0 & 1 & 0.19 & 0.52 \\
\hline 12 & 0 & 1 & 0.44 & 0.32 \\
\hline 13 to 15 & 0 & 1 & 0.16 & 0.16 \\
\hline 16 or more & o & 1 & 0.22 & -- \\
\hline \multicolumn{5}{|l|}{ Personal/spousal occupation } \\
\hline Manual & 0 & 1 & 0.23 & 0.64 \\
\hline Skilled & 0 & 1 & 0.39 & 0.23 \\
\hline White collar & o & 1 & 0.38 & 0.13 \\
\hline \multicolumn{5}{|l|}{ Adult child's schooling } \\
\hline o to 12 & 0 & 1 & 0.26 & 0.39 \\
\hline 13 to 15 & 0 & 1 & 0.22 & 0.25 \\
\hline 16 & 0 & 1 & 0.27 & 0.21 \\
\hline 17 or more & o & 1 & 0.26 & 0.14 \\
\hline \multicolumn{5}{|l|}{ Controls } \\
\hline Average family wealth (in units of $\$ 10,000$ ) & 0 & 166 & 7.83 & 1.10 \\
\hline Lived with biological parents at 15 & 0 & 1 & 0.78 & 0.54 \\
\hline Divorced one or more times & 0 & 1 & 0.17 & 0.23 \\
\hline Lives in the South & 0 & 1 & 0.30 & 0.68 \\
\hline Number of children & 1 & 21 & 3 & 4 \\
\hline Most educated child is female & 0 & 1 & 0.50 & 0.55 \\
\hline
\end{tabular}

Note:

- Values in this table are based on 20 complete datasets.

- Average family wealth is presented in constant 2016 dollars, but it is logged and standardized prior to imputation and analysis. 

Table 2. Exponentiated Parameter Estimates (Hazard Ratios) with 95\% Confidence Intervals from Gompertz Proportional Hazards

Models using White Sample $(\mathrm{N}=2,432)$

\begin{tabular}{|c|c|c|c|c|c|c|c|c|c|c|}
\hline & \multicolumn{2}{|c|}{ Model 1} & \multicolumn{2}{|c|}{ Model 2} & \multicolumn{2}{|c|}{ Model 3} & \multicolumn{2}{|c|}{ Model 4} & \multicolumn{2}{|c|}{ Model 5} \\
\hline & $\mathrm{HR}$ & $95 \% \mathrm{Cl}$ & $\mathrm{HR}$ & $95 \% \mathrm{Cl}$ & $\mathrm{HR}$ & $95 \% \mathrm{Cl}$ & $\mathrm{HR}$ & $95 \% \mathrm{Cl}$ & $\mathrm{HR}$ & $95 \% \mathrm{Cl}$ \\
\hline \multicolumn{11}{|l|}{ Parent schooling (ref. o-6) } \\
\hline 7 to 11 years & 0.97 & $0.81,1.17$ & & & & & 1.04 & $0.85,1.26$ & 1.04 & $0.85,1.26$ \\
\hline 12 or more years & $0.80^{*}$ & $0.64,0.98$ & & & & & 0.97 & $0.77,1.22$ & 0.97 & $0.78,1.22$ \\
\hline \multicolumn{11}{|l|}{ Parent occupation (ref. manual) } \\
\hline Farming & $0.82^{*}$ & $0.68,0.98$ & & & & & $0.80^{*}$ & $0.66,0.96$ & $0.82^{*}$ & $0.68,0.98$ \\
\hline Skilled & 0.84 & $0.70,1.01$ & & & & & 0.90 & $0.75,1.08$ & 0.92 & $0.76,1.10$ \\
\hline White collar & 0.93 & $0.76,1.15$ & & & & & 1.08 & $0.87,1.33$ & 1.10 & $0.89,1.37$ \\
\hline \multicolumn{11}{|l|}{ Personal/spousal schooling (ref. o-11) } \\
\hline 12 years & & & 0.88 & $0.75,1.05$ & & & 1.05 & $0.87,1.25$ & 1.09 & $0.91,1.31$ \\
\hline 13 to 15 years & & & 0.80 & $0.64,1.01$ & & & 1.09 & $0.85,1.39$ & 1.14 & $0.89,1.45$ \\
\hline 16 or more years & & & $0.66^{* * *}$ & $0.52,0.85$ & & & 0.94 & $0.71,1.24$ & 0.99 & $0.75,1.30$ \\
\hline \multicolumn{11}{|c|}{ Personal/spousal occupation (ref. manual) } \\
\hline Skilled & & & 0.87 & $0.74,1.03$ & & & 0.88 & $0.74,1.04$ & 0.89 & $0.75,1.05$ \\
\hline White collar & & & $0.80^{*}$ & $0.66,0.97$ & & & $0.81^{*}$ & $0.66,0.99$ & 0.84 & $0.68,1.02$ \\
\hline \multicolumn{11}{|l|}{ Adult child schooling (ref. 0-12) } \\
\hline 13 to 15 Years & & & & & $0.77^{* *}$ & $0.65,0.93$ & $0.79^{*}$ & $0.66,0.95$ & $0.82^{*}$ & $0.68,0.99$ \\
\hline 16 years & & & & & $0.68^{* * *}$ & $0.57,0.81$ & $0.71^{* * *}$ & $0.59,0.86$ & $0.74^{* *}$ & $0.61,0.89$ \\
\hline 17 or more years & & & & & $0.53^{* * *}$ & $0.44,0.64$ & $0.57^{* * *}$ & $0.46,0.70$ & $0.59^{* * *}$ & $0.48,0.74$ \\
\hline Average family wealth & & & & & & & & & $0.87^{* * *}$ & $0.81,0.94$ \\
\hline Lived with biological parents at 15 & $0.82^{* *}$ & $0.71,0.95$ & $0.83^{*}$ & $0.72,0.96$ & $0.86^{*}$ & $0.74,1.00$ & 0.88 & $0.76,1.03$ & 0.90 & $0.77,1.04$ \\
\hline Divorced one or more times & $1.32^{* * *}$ & $1.12,1.56$ & $1.31^{* *}$ & $1.11,1.55$ & $1.31^{* *}$ & $1.12,1.55$ & $1.31^{* *}$ & $1.11,1.54$ & $1.22^{*}$ & $1.03,1.44$ \\
\hline Lives in South & $1.21^{* *}$ & $1.05,1.39$ & $1.16^{*}$ & $1.01,1.34$ & 1.11 & $0.97,1.27$ & $1.16^{*}$ & $1.01,1.34$ & 1.15 & $1.00,1.32$ \\
\hline Number of children & & & & & 1.00 & $0.96,1.03$ & 1.00 & $0.96,1.03$ & 0.99 & $0.96,1.03$ \\
\hline Daughter has the most schooling & & & & & 0.89 & $0.78,1.01$ & 0.88 & $0.78,1.01$ & $0.88^{*}$ & $0.77,1.00$ \\
\hline
\end{tabular}

Note:

$* p \leq 0.05, * * p \leq 0.01, * * * p \leq 0.001$ (two-tailed tests)

- $\quad$ Average family wealth is logged and standardized prior to imputation and analysis

- Models that include adult child education also adjust for the year that adult child information was collected. 
Table 3. Exponentiated Parameter Estimates (Hazard Ratios) with 95\% Confidence Intervals from Gompertz Proportional Hazards Models using Black Sample $(\mathrm{N}=917)$

\begin{tabular}{|c|c|c|c|c|c|c|c|c|c|c|}
\hline & \multicolumn{2}{|c|}{ Model 1} & \multicolumn{2}{|c|}{ Model 2} & \multicolumn{2}{|c|}{ Model 3} & \multicolumn{2}{|c|}{ Model 4} & \multicolumn{2}{|c|}{ Model 5} \\
\hline & $\mathrm{HR}$ & $95 \% \mathrm{Cl}$ & $\mathrm{HR}$ & $95 \% \mathrm{Cl}$ & $\mathrm{HR}$ & $95 \% \mathrm{Cl}$ & HR & $95 \% \mathrm{Cl}$ & $\mathrm{HR}$ & $95 \% \mathrm{Cl}$ \\
\hline \multicolumn{11}{|l|}{ Parent schooling (ref. o-6) } \\
\hline 7 to 11 years & 1.08 & $0.86,1.35$ & & & & & 1.14 & $0.90,1.45$ & 1.16 & $0.91,1.47$ \\
\hline 12 or more years & 0.96 & $0.67,1.37$ & & & & & 1.08 & $0.75,1.56$ & 1.07 & $0.74,1.56$ \\
\hline \multicolumn{11}{|l|}{ Parent occupation (ref. manual) } \\
\hline Farming & $0.80^{*}$ & $0.65,0.99$ & & & & & $0.79^{*}$ & $0.63,0.98$ & $0.80^{*}$ & $0.64,0.99$ \\
\hline Skilled or white collar & 0.99 & $0.71,1.39$ & & & & & 1.17 & $0.83,1.65$ & 1.17 & $0.83,1.65$ \\
\hline \multicolumn{11}{|l|}{ Personal/spousal schooling (ref. 0-11) } \\
\hline 12 years & & & 0.97 & $0.78,1.19$ & & & 0.96 & $0.77,1.20$ & 0.98 & $0.79,1.22$ \\
\hline 13 or more years & & & 0.76 & $0.55,1.04$ & & & 0.82 & $0.58,1.15$ & 0.85 & $0.60,1.19$ \\
\hline \multicolumn{11}{|l|}{$\begin{array}{l}\text { Personal/spousal occupation (ref. } \\
\text { manual) }\end{array}$} \\
\hline Skilled & & & 0.96 & $0.76,1.21$ & & & 0.92 & $0.72,1.17$ & 0.96 & $0.75,1.22$ \\
\hline White collar & & & 0.75 & $0.54,1.04$ & & & 0.85 & $0.61,1.18$ & 0.91 & $0.65,1.28$ \\
\hline \multicolumn{11}{|l|}{ Adult child schooling (ref. 0-12) } \\
\hline 13 to 15 Years & & & & & 0.84 & $0.66,1.07$ & 0.85 & $0.66,1.08$ & 0.88 & $0.69,1.13$ \\
\hline 16 years & & & & & $0.74^{*}$ & $0.57,0.96$ & $0.74^{*}$ & $0.56,0.98$ & 0.78 & $0.59,1.04$ \\
\hline 17 or more years & & & & & $0.47^{* * *}$ & $0.34,0.64$ & $0.48^{* * *}$ & $0.34,0.68$ & $0.51^{* * *}$ & $0.36,0.72$ \\
\hline Average family wealth & & & & & & & & & $0.87^{* *}$ & $0.79,0.95$ \\
\hline Lived with biological parents at 15 & 1.06 & $0.88,1.28$ & 1.04 & $0.87,1.24$ & 1.00 & $0.83,1.20$ & 1.04 & $0.86,1.26$ & 1.06 & $0.87,1.28$ \\
\hline Divorced one or more times & 0.93 & $0.75,1.17$ & 0.95 & $0.76,1.19$ & 0.92 & $0.74,1.15$ & 0.91 & $0.73,1.14$ & 0.87 & $0.69,1.10$ \\
\hline Lives in South & 0.93 & $0.76,1.14$ & 0.85 & $0.70,1.04$ & 0.88 & $0.73,1.08$ & 0.93 & $0.75,1.14$ & 0.94 & $0.76,1.16$ \\
\hline Number of children & & & & & 1.02 & $0.99,1.05$ & 1.01 & $0.99,1.04$ & 1.01 & $0.98,1.04$ \\
\hline Daughter has the most schooling & & & & & 0.88 & $0.73,1.06$ & 0.88 & $0.73,1.07$ & 0.87 & $0.72,1.06$ \\
\hline
\end{tabular}

Note:

- $\quad * p \leq 0.05, * * p \leq 0.01, * * * p \leq 0.001$ (two-tailed tests)

- $\quad$ Average family wealth is logged and standardized prior to imputation and analysis.

- Models that include adult child education also adjust for the year that adult child information was collected. 
Figure 1: Baseline Predicted Survival Curves by Race, Familial Generation, and Educational Attainment

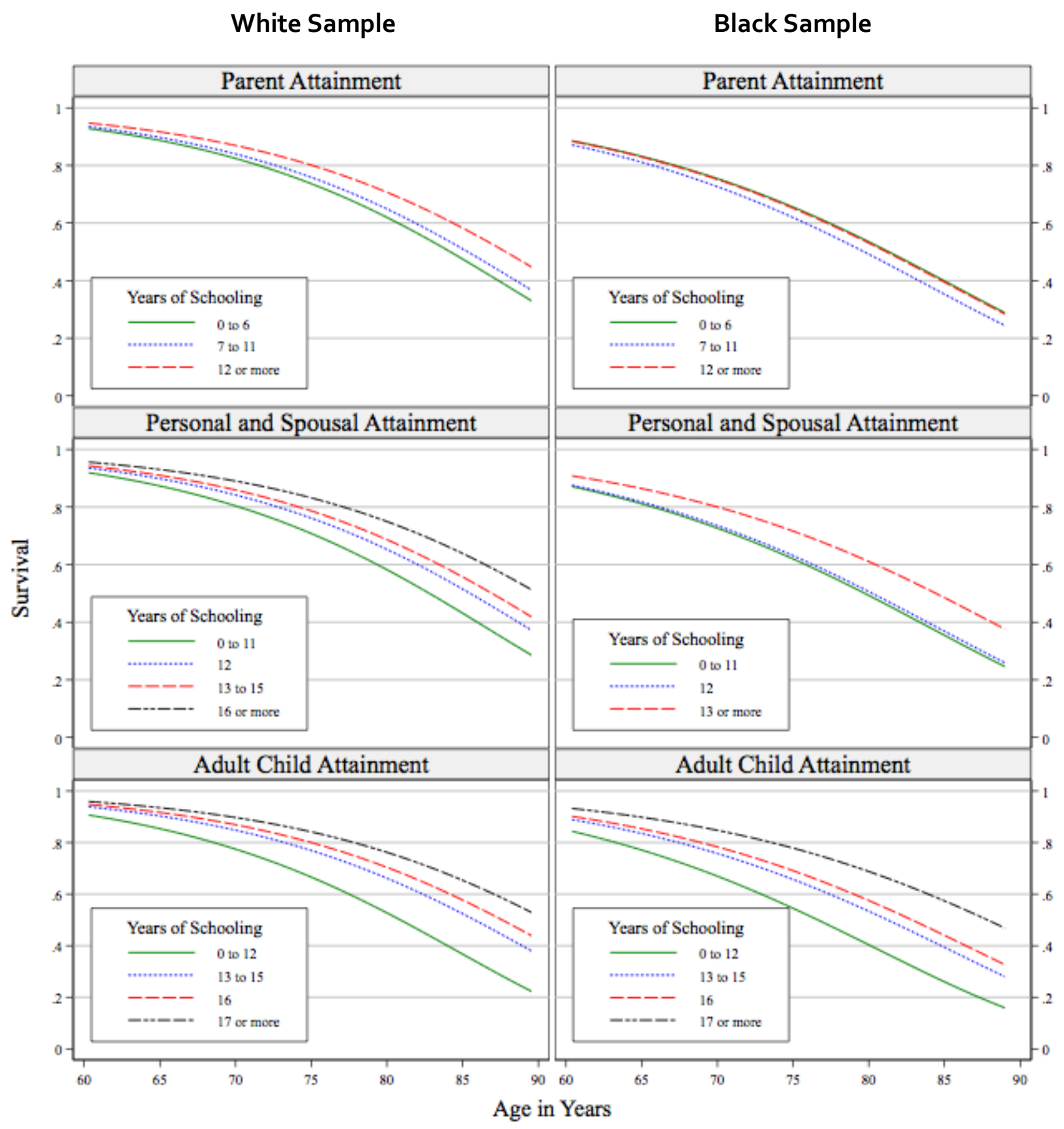


Figure 2: The Estimated Median Age of Death by Race and the Attainments of Adjacent Generations

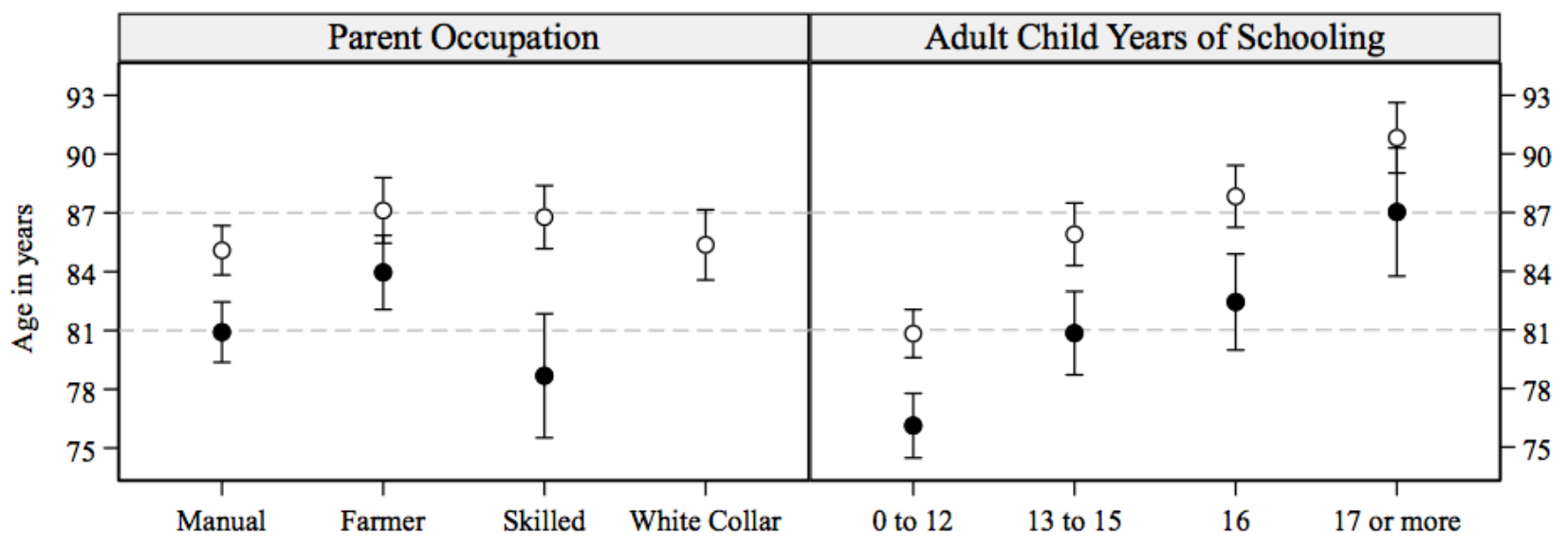

White sample median age of death

Black sample median age of death

Note:

- $\quad$ Dashed lines represent the unadjusted median age of death for white women at 87 years old and for black women at 81 years old.

- $\quad$ Predictions are based on a reduced model that excludes personal educational and occupational attainments and includes interactions between race and all other variables.

- Median life expectancies were estimated while holding all other variables at their observed values.

- $\quad$ Although the confidence intervals are overlapping for "Farmer" in the first panel, the difference in the median age of death between white and black women is significant $(p<.05)$. However, the difference is not significant $(p>.05)$ between the median age of death for the white and black sample in the "17 or more" category in the second panel 